\title{
Aesthetic Form of Costume Series Design with Harmony Principle
}

\author{
Sijing Lu, Yinghui Chang \\ Jiangxi Science \& Technology Normal University, Nanchang City, Jiangxi Province, postcode 330013
}

Keywords: Harmony principle; Costume series design; Aesthetic form; Research analysis

\begin{abstract}
It is an important link to present harmony principle during costume series design in costume design. This paper is based on cultural qualities; costume series design is conducted by approaches of literature method, observation method, comparison method and so on with harmony as principle, and its aesthetic form is studied. Harmony principle presents diversity in costume design, and there are different forms of the integration of unity and contradiction in costume aesthetic. Artistic modeling and creation styles presented during costume design strengthen visual impact of costume design greatly. Application of color and selection of materials are important links in harmony principle. Types, styles and technology serve as a foil so that costume design can catch up with the development trend of modernization and become the fashion front and aesthetic mainstream of social development.
\end{abstract}

\section{Introduction}

With the stable and healthy development of economic society, people's ideology and aesthetic philosophy become increasingly diversified, so does their pursuit for costume fashion trend. Costume series design is a special artistic form that is generated under the background of rapid economic development. It means diversified costume art processing under certain aesthetic style, thereby reaching maximization of economic benefits of costume series design. However, to realize ideal economic benefits in market environment, some fashionable elements need to be integrated into costume design perfectly. At present, some advanced high technology means are applied in costume series design technology, thereby presenting different and novel fashionable costume of complete set with similar design.

\section{Cultural quality core of costume series design}

Design is the forms of things in people's heart, and it is completed by process and making, while series means a group of things that have certain connection and keep changing. Costume series design refers to: over two sets of integrate and connecting costumes that have similar elements and are formed according to certain order. Under general circumstances, costume series can be divided into 1, binary series, 2, small series 3--4 sets, 3, medium series 5--6 sets, 4, large series 7--8 sets, 5, extra large series over 9 sets. Though people's costume design and production come from the fourth glacial period, contemporary design and production come from the one hundred years in which class and huge gender difference were eliminated. It carries out fashionable costume creation with a certain cultural philosophy as the center, and even conducts market investigation actively and reach modern commercialization form. Costume series design became mature gradually from the 1960s.

\section{Harmony principle of costume series design}

Mr. Zhu Kai, a modern design theory scholar and educator, once pointed out that harmony is one of the characteristics of beauty and the optimum plan of constitution. Harmony means automatic changes between difference and unity, while harmony principle is an important philosophy in art design. Costume design is also an aesthetic representation. Themes, types, color, models, 
technology and so on are the form elements. Costume design can integrate different elements, and its approaches can present logic. Under this condition, the major direction of costume series design is the organic integration of costume art design and costume visual type, and relevance is valued on the basis of the artistic form of costumes. Concerning the reasons, the highest artistic realm of various changing states from different numbers of form units is harmony.

\section{Presentation of harmony principle in costume series design}

Under general conditions, people feel the existence of costume space by vision and touching. From the perspective of time changes, visual perception is ahead of touching perception. When people are conducting costume series cognition, the connection between different costumes is an important basis for costume core to assist carrier analysis. Though based on theoretical analysis, only integrating some primary color production interaction in costumes can reach series design. However, cognition formed during different forms of costume design might be different. From different cognition tests, it is not hard to find out that different types of form elements are presented in costume series design with different forms of harmony principle. Themes, models, colors and material elements are the core, while types and technology are subsidiary.

The essence of diversification is different forms, while harmony means "harmony in diversity". Its optimum effect is represented in the freshness of visual organs in the latest stage, and specific subtle details are felt in experience. Under this background, it still needs more consideration to present large span and the same area of comparison color in the same series of costume design. Therefore, in order to keep up with the fashoanble development trend, the appearance of costumes in the 21st century highlights fitness and relaxation, thereby satisfying people's movment requirement. Taking advantage of the changes, peculiarities, constitution and decoration of materials becomes a major direction of costume series design. For example, in Kenzo2008 autumn and winter advanced ready-to-wear series design, simple A form and $\mathrm{H}$ form dresses are presented by dead color series, and the materials are diversified. According to the texture, it is divided into: knitting and tatting; according to the patterns, it is divided into flower fabric and plain fabric; according to pattern technology, it is divided into Jacquard and printed fabric. Flower is the unitive theme element, and its pattern and styles are numerous; the presentation technology is divided into knitting, embroidery, applique, frosting, etc.

In Valentino 2013 autumn and winter advanced ready-to-wear series design, Chinoiserie Chinese blue and white porcelain was used as the theme. The combination of blue and white is the major tonality with different lengths. Various patterns were presented in various texture materials. Among them, it is divided into woof with ancient sense, elegant location printing yarn, embroidered lace and dermatoglyphic pattern embroider in knitted fabric.

Unified processing of similar elements means hiding minute differences by adjusting forms. Color is people's first perception, the most diversified information and form elements that are easy to be quantized and analyzed. By impacts of color, perception and experience of color are motivated with imagination. Color is the first element that every designer grasps in costume series design, and the adjustment of tones is rational. Since colors can be cleaned, different colors are located by lightness, hue and purity. Neutral color collocation, the same type of hue and compared hue and other forms are used in costume series design, which can present the relationship between costume style and series. For example, in Empoorio Armani2014 spring and summer advanced ready-to-wear series design, in different costumes, the relationship between the design and form of colors and between location of area and visual core as well as color expression similarity of different costumes all have important influence on the harmony of the integral series of costumes.

Comparison is an extreme integration, in which elements with distinct difference can integrate with each other. Costume design and perception are relative, and it is antagonistic form with quantity and lightness changes of elements. The most frequently used methods in costume series design are: overturning costume identity and preventing costume tradition, setting spatial relation and costume materials, seasonal transition and gender connection. Concerning materials, integrating materials with different functions can weaken the property of costumes. Only the themes, 
appearance and colors of costume series design need to be designed, and harmony with innovation can be presented.

For example: integrating interest in the previous orthodox men's suit three-piece, materials with patterns and jacquard weaving materials with bright colors are chosen, hollow embroidery and applique are applied for modeling. Besides this, cropped trousers, selection of hats and styles with similar colors with the jacket and trousers are chosen to present theme effects. In Thom Browne 2016 spring summer design, orthodox and classic styles are overturned to present flexible and lively feelings. Or in Dolce\&Gabanna autumn and winter advanced ready-to-wear series design, Napoleon era is used as the theme, and modern men and women costume elements are integrated in women's wear series design. In modern society, men's and women's costumes have many differences and the styles and characteristics are also different. Re-combining the elements can present abundant reminiscence in the overall costume series, and women's handsomeness is not lost as well.

\section{Harmonious age characteristics presented in costume series design}

The present costume series design changes with changes of market economy and improvement of life quality, and it presents different styles and features sufficiently. The presentation of harmony in costume series design is also the presentation of modern society. Since costume aesthetics begins to converge with creation, and it transfers from horizontal mobility to public selection. Costume series design is at development stage, and it is bound to change in certain changing form unit.

In an individual costume series design which was held by a designer a long time ago, it was called "8" by people and Corolle by Mr. Dior. It became a benchmarking costume series design in the industry at that time. This style became the mainstream instantly, and was called a much-told tale in which harmony conquered all. At that time, people could enjoy tranquility and women's charm and attraction were fully presented.

Compared with military uniforms produced in time of war, in which food and material resources were in severe shortage, European women's traditional beauty in the 16th century was integrated in the costume design. Design in this period adopted the smooth natural shoulder line, full and high breast models and slim waist as major characteristics, and the difference is changes of materials, from Tuff to wool lining, from flower color to milky white a, leopard print, etc. After decades of evolution, "trans Dior" began to highlight changes, inheritance and innovation, and the length of dress combination series began to be at the middle of shanks and above kneels, and patterns were embroidered on dresses. Modern Alice garden, pop art and modernism styles were originated from the second decade of the new century, when people began to realize future development would be the theme of women, and women should have modern ideology. Different series of difference indicate that classic conform with crude. However, under various modern background, people's thoughts begin to be diversified, and their aesthetic characteristic also have new changes. Costume series design improves people's life by costume practice forms, thereby improving people's requirements for individual costumes and promoting industrial progress and development. Harmony element in philosophy is applied in costume series and beautified, thereby becoming a key technology principle in costume series design.

Costume series design comes from series design from similar elements, while harmony principle is the community. When people are in costume series perception, harmony principle is the first impression analysis, and the impression is the extension of following-up costumes and the relationship between human and costumes. In costume series design, appearance, color and material with strong stimulation assist carriers, such as technology, type, structure, etc. The integration of different forms of elements connect to an integral integrity, and present the relationship between

part of the fixed elements in different degrees. The premise of costume design is aesthetics, and aesthetic in different periods change with changes of time.

\section{Conclusion}

Costume series design enriches time life, and it is promoting the healthy development of costume 
industry with innovative philosophy. The author makes the analysis from four aspects, which are cultural quality core, harmony principle, presentation of harmony principle and harmonious age. Harmonious beauty has time characteristics, and it is especially prominent in satisfying people' life. Costume series design can improve life and realize commercial economic benefits, and aesthetic characteristics also present diversified characteristic with changes of the society.

\section{References}

[1]Zhuang Pengji. Application of Traditional Chinese Elements in Costume Design_-Appreciation of "Tianqingyanyu" Work of Chinese Best Ten Costume Designer Deng Zhaoping [J]. Meliand China, 2015(11).

[2] Liu Shuang. Research and Series Design of Chinese Style Endowed with Modern Sense[J]. Western Leather, 2016(08).

[3] Wang Weijing, Li Yanxiao. Aesthetic Principles of Chinese Paper Cutting Art and Its Application in Costume Design [J]. Silk, 2016(05).

[4] Qian Mengyao, Cai Xin. Costume Series Design Aesthetic Form of Harmony Principle [J]. Silk, 2014(12).

[5] Pan Zhiguang. Creation of Issey Miyake and Reflection on Contemporary Costume Aesthetics [J]. Modern Decoration (Theory ) ,2015(01).

[6] Smart Costume Can Work as Antenatal Care Tracer [J]. Progress of Weaving Technology, 2015(01).

[7] Zhao Chenhui, Zhang Qingxia. Application of National Lining in Modern Costume Design_—With Bandhnu as Example [J]. Journal of Jiaxing University, 2014(03). 